\title{
Yükseköğretimde Kapsayıcılığın Uygulanabilirliği Üzerine bir Tartışma
}

\author{
DOI: 10.26466/opus.755015
}

*

\author{
Asu Altunoğlu * \\ * Dr. Öğr. Üyesi, Anadolu Üniversitesi, Açıköğretim Fakültesi, Eskişehir/Türkiye \\ E-Posta: asualtunoglu@anadolu.edu.tr \\ ORCID: $\underline{0000-0002-2649-5262}$

\section{Öz}

Yükseköğretime katılım tüm dünyada giderek artan bir şekilde gerçekleşmektedir. Bu doğrultuda yükseköğretimin toplumun refahını ve sosyal adaleti sağlamaya yönelik misyonu ile öne çıktığı ve her zamankinden daha önemli bir aktör haline geldiği söylenebilir. Katılımın genişlemesi, toplumun tüm kesimlerinin dahil edilmesini kolaylaştırmıs gibi görünse de pek çok ülkede bu genişleme ile öğrenci kitlesinin gerçek anlamda heterojen bir yapıya büründüğ̈̈ görülmemiştir. Bu nedenle, eğitimde eşitlik ve ayrımcllığa karşıtlık temelinde ihtiyaç duyulan kapsayıcılık kavramı, yükseköğretimde de tartışılmaya başlanmıştır. Bu çalışma bu tartışmaya, kapsayıcılık literatüründe de henüz yeterli düzeyde değinilmemiş olan öğrenme kültürü ve öğrenme topluluğu olma kavramların temel alarak, öğrenme kültürleri, çevrimiçi öğrenme ve açık ve uzaktan öğrenmenin yükseköğretimi kapsayıcı hale getirmedeki rolü üzerinde düşünerek katılmayı amaçlamaktadır. Kapsayıcılığın literatürde genellikle bireylerin bedensel ve zihinsel yapabilirlik kapasitelerindeki farklılıklara bir vurguyla ele alındığı ortaya konmuş, daha anlaml hale gelmesi için açı ve uzaktan öğrenmenin yükseköğretime sunduğu firsatlar olduğu sonucuna varılmıştır.

Anahtar Kelimeler: $\quad$ yükseköğretim, kapsayıcılık, katılım, öğrenme kültürleri, açık ve uzaktan öğrenme 


\title{
Applicability of Inclusiveness in Higher Education
}

\begin{abstract}
Participation in higher education has been expanding throughout the world. This has resulted in the fact that the mission of higher education that aims to enhance social justice and welfare for all in the society has gained significance and thus it has become a more important actor. The expansion of participation, though, has not exactly caused a real heterogeneity in the student composition especially in terms of learning outcomes. This is why the concept of inclusiveness was introduced into the discussions of the issues of equality and discrimination in higher education. This study aims to contribute to these discussions with an emphasis on learning cultures and learning communities, through opening paths of thought on how online learning or open and distance learning may increase inclusiveness in higher education. It appears that the literature on inclusiveness has mostly focused on the differences between the physical and mental capabilities of individuals, which needs to be changed. Open and distance learning could provide us with many opportunities in this direction.
\end{abstract}

Keywords: Higher education, inclusiveness, participation, learning cultures, online learning, open and distance learning 


\section{Giriş}

Bu çalışma günümüz dünyasında yükseköğretime atfedilen değerler ve misyonlara ilişkin mevcut tartışmaları, bu değerlerin en yenilerinden olan kapsayıcllık ve onun temellendiği sosyal adalet kavramı ekseninde katkılar sunarak zenginleştirmeyi amaçlamaktadır. Kapsayıcılığı yükseköğretim için uygulanabilir bir strateji haline getirmenin yolları üzerine düşünebilmek amaciyla yükseköğretimin değer ve misyonları arasında nereye oturduğunun tartışlabilmesine yönelik bir teorik hazırlık mahiyetindedir. Yükseköğretimin bu çalışma kapsamında ele alınamayacak kadar çeşitli değer ve misyonu olduğundan, kapsayıcılık literatüründe de henüz yeterli düzeyde değinilmemiş olan öğrenme kültürü ve öğrenme topluluğu olma kavramları kapsayıcılığın yükseköğretimde tartışılmasının merkezine alınacaktır. Dünyada her şey son derece baş döndürücü bir hızla değişirken aynı zamanda tüm bildiklerimize meydan okuyan krizler baş göstermektedir. Tartışmanın somutlaştırılmasına bir örnek teşkil etmesi adına, bu krizlerin en günceli olan Covid19 pandemisinin yükseköğretimdeki yansımalarına özellikle kapsayıcılık açısından bakılacaktır.

Buna yönelik olarak, bu yazıda yükseköğretimde eşitlik meselesine kapsayıcılık, sosyal adalet ve etik açlardan da bakmayı mümkün kılan ve rehberlik, planlama ve karar alma gibi yönetimsel işlevleri de sorgulayan meta düzeyde bir bakış açısından yararlanılmıştır. Buna göre, 21. yüzyıl üniversitesi, ırk, etnisite, cinsel kimlik, cinsel yönelim, din, sınıf, fiziksel ve bilişsel yapabilirlik kapasitesi bakımından bir ayrıma maruz bırakılmaksızın tüm bireylerin birlikte bir bilgi üretimi ve topluluk inşası sürecine dahil oldukları profesyonel bir öğrenme topluluğudur.

Tüm dünyada yükseköğretim kurumlarının gelişiminde özellikle kurumsal biçimlerin farklılaşması ve çeşitliliği olarak kendini gösteren değişim gözlemlenmektedir. Bu kurumsal biçimlerden bazılarına küçük ölçekli kolejler, uygulamalı bilimler üzerine uzmanlaşmış üniversiteler ve global çevrimiçi üniversiteler örnek gösterilebilir. Bu değişimin Türkiye'de hangi biçimlerde ve ne ölçüde gerçekleştiğinin değerlendirilmesi gerekmektedir.

UNESCO'nun sürdürülebilir kalkınma hedefleri genel olarak eğitimle ilgili açılık ve kapsayıcılık değerlerini vurgulamakta, özellikle açık eğitim 
kaynaklarının uzaktan ya da örgün tüm eğitim türleri ve aşamalarında yaşamboyu öğrenmeye katkı sağlamak amacıyla hayata geçirilmesinin kapsayıcılığı artıracağını öngörmektedir (Ossiannilsson, 2019).

Bu sürdürülebilir kalkınma hedefine yönelik amaçlardan 5 tanesi yükseköğretimle ilişkili olduğundan, yükseköğretimin giderek daha önemli bir aktör haline geldiği söylenebilir (Boni, Lopez-Fogues ve Walker, 2016). Sanayi toplumunun en önemli kurumları sanayi ve devlet iken, günümüz sanayi sonrası bilgi toplumunun anahtar kurumları sanayi ve devletle birlikte kendi kurumsal kimlikleri ile üniversitelerdir (Etzkowitz ve Kloftsen, 2005); dolay1sıyla sürdürülebilir kalkınma hedefleri içinde önemli yer tutmaları doğaldır. Fakat unutulmamalıdır ki küresel yönetişimin ürünü olan kalkınma programlarının yükseköğretimle ilgili vizyonu genellikle iş piyasasına insan sermayesi yetiştirmektir. Üniversitenin sanayiyi ve ekonomiyi şekillendiren önemli kurumlardan biri olduğuna dair bu vizyon OECD ve Dünya Bankası gibi diğer bir çok kuruluş tarafından da paylaşılmaktadır. Bu durum yükseköğretimin niteliği ile ilgili daha hesap verebilir ve karşılaştırılabilir bir noktada olmasını gerektirmektedir. Çoğunlukla nicel düzlemde yapılan bu karşllaştırmalar ve kalite ölçme ve değerlendirme çalışmaları ise, katılıma kayıt sayıları düzeyinde baktığından, eşitsizlikler ve ayrımclık gibi konularda s1nırlı veri sunduğu gibi, öğrenme-öğretme süreçlerinin niteliği ve kapsayıcllığı gibi konulara neredeyse hiç değinilmemektedir. Bu nedenle bahsedilen kalkınma hedeflerinin daha sürdürülebilir olması yükseköğretimde sosyal adalet ve kapsayıcılık gibi kavramların tartışılması ile olabilir. Bunun için yükseköğretimin işgücüne katkısını vurgulayan insan sermayesi yaklaşımı yerine toplumun ve bireyin gelişimini ve refahını eşit ve adil bir biçimde artırmayı hedefleyen sosyal adalet yaklaşımından yararlanılacaktır.

\section{Kapsayıcılık Kavramı}

Topluluk halinde yaşayan insanlar bir değerler kümesi oluştururken aynı zamanda bu değerler aracılığıyla kendi aralarından bazılarını içe alma diğerlerini de dışarıda bırakma pratiğini hayata geçirirler. Bu dışarıda bırakma pratiği dinsel inanış, etnik köken, cinsiyet, ya da başka başka kimlikleri nedeniyle kimi insanlara uygulanırken, onların değer yitimine ve ötekileştirilmesine neden olur. Dışlanmanın hedefinde fiziksel ya da zihinsel yapabilirlik kapasitesi nedeniyle farklılığa ya da istisnai duruma sahip bir birey varsa bu değer 
yitiminin daha ağır sonuçları olabilmektedir. Kapsayıcılık bu dışlama alışkanlıklarını güçsüzleştirmeyi ve dolayısıyla daha demokratik bir toplum inşa etmeyi amaçlayan bir ideal olarak ortaya çıkmıştır. Bu bağlamda, kapsayıcılığı daha iyi anlayabilmek için demokratik bir toplum idealinin teorik ve tarihsel kökenine dair kısa bir değerlendirmeye ihtiyaç vardır.

Demokratik bir toplumda, etnik köken, din, cinsiyet, yaş ya da yapabilirlik kapasitesi ne olursa olsun tüm insanlar, birlikte yaşamak için gerekli olan tüm kamusal haklar ve mallardan faydalanmakta eşit haklara kendiliğinden sahiptir. Bu önkabul günümüzde toplumun sınırları açısından daha küresel bir bakış açısıyla değerlendirilmekte, demokrasi sadece tekil bir toplum açısından değil, milli, etnik ve kültürel sınırları aşacak şekilde küresel bir ahlaki ve siyasi ideal olarak algılanmaktadır. Bugünün çok kültürlü toplumlarında çeşitlilik içinde bir arada olabilmenin şartı olarak küresel demokrasi fikri ortaya çıkmış, bu fikrin gerçekleştirilmesi için de temel olarak ahlaki eşitlik ilkesinden yararlanılmıştır (Snauwert, 2002). 'Ahlaki eşitlik' ilkesi, Kant (2002) tarafından şu şekilde açıklanmıştır: "insan ve genel olarak her akıl sahibi varlık, şu veya bu isteme için rastgele kullanılacak sırf bir araç olarak değil, kendisi amaç olarak vardır ve gerek kendine gerekse başka akıl sahibi varlıklara yönelen bütün eylemlerinde hep aynı zamanda amaç olarak görülmelidir" (s. 96). İnsanın araç değil amaç olarak kabul edilmesi şartı her insanı eşit onura sahip ve her insanın akla dayalı davranışını saygıya değer görmemizi sağlar.

Eşit onura ve saygıya layık tüm insanlar, toplumdan eşit sosyal destek alarak kendilerini özgürce ifade edebilecekleri gelişim firsatlarına kavuşurlarsa, demokratik toplum amacına ulaşmış olacaktır. Bunun için her bireyin kendine özgü yeteneklerini ve çabasını toplumun potansiyelini güçlendirmek için kullanabileceği koşullar oluşturulmalıdır (Dewey, 1976). Dewey'e göre (1976) ahlaki eşitlik ilkesi tüm insanları eşit istekler ya da yeteneklere sahip olarak kabul etmemiz değil, tam tersine söz konusu yönlerden farklılaşan bireylerin bu farklılıkların oluşturabileceği adaletsizliklere maruz kalmaması için kabul etmemiz gereken bir demokrasi şartıdır. Birbirinden yaş, cinsiyet, ya da başka özellikler açısından farklı bireyler olsa da, bu farklılıkların hiçbiri herhangi bir bireyi hiyerarşik olarak diğerinden daha değerli ya da daha değersiz yapmaz. Demokratik bir toplumun özü bireysel farklılıklara dayalı karşılaştırılamazlık ilkesi olmalıdır.

Eğitimin amacı küresel demokrasi ideali doğrultusunda bireylere toplumun iyiliğine yönelik demokratik süreçlerde yer almaları için fırsatlar ve 
alanlar sunmaktır. Bu noktada Banks (1996) demokrasinin yalnızca küresel bir ideal olarak değil, insanlığın iyiliği ve gelişmesi amacı için bireylerin birbiriyle etkileşim kurduğu kişisel, toplumsal ve mesleki rutinlerinde bir doğal günlük pratik olarak yer alması gerektiğini vurgulamıştır. Bu günlük pratiğin en önemli bileşeni olan okullar çocukların toplumun bir parçası olmayı öğrendikleri yerler değil, toplumun kendisidir. Toplum okulda başlayıp oradan duvarların ötesine, sokaklara ve çarşılara doğru uzanır (Shyman, 2013). Dolayısıyla, 'kapsayıc bir eğitim' liberal ve çoğulcu bir demokrasinin ilkelerini benimsemeli ve böylece gençlere demokratik bir yaşamı, içinde olarak, onu geliştirerek ve ona katkı sunarak deneyimleme fırsatı sağlamalıdır (Allan ve Slee, 2008).

Kapsayıcilık hem toplumda hem de toplumun kurucu bir unsuru olarak eğitimde eşitlikçilik ve ayrımcılığa karşıtllık temelinde tartışılmaya başlanmış, eğitimin toplumdaki rolü ve dezavantajlı bireylerin eğitimle ilişkisi ile ilgili yaşanan teorik ve pratik açmazlara cevap olmak üzere geliştirilmiş bir kavramdır. Eğitim toplumsal dayanışma, grup kimliği edinme ve topluluk bilincine kavuşma alanıdır (Carlson ve Apple, 1998). Fakat eğitimin gerçekleştiği kurumların kültürü ve iklimi aynı zamanda bazı bireyler için yabancılaşmayla sonuçlanabilecek süreçlere zemin hazırlayabilmektedir.

Sosyal adalet fikrinin tam anlamıla içselleştirilmesinin ve aynı zamanda uygulanmasının kapsayıclık olmadan gerçekleşemeyeceği günümüzde ortaya çıkmıştır. Bu nedenle, kapsayıcılığın nasıl uygulanacağı da sosyal adalet fikrinin ne anlama geldiği ve algılanma biçimi ile doğrudan ilgilidir.

Kapsayıcilık tüm bireylerin toplumsal ve siyasal toplulukta eşit mesafede olma hakkı ve toplumun üyelerinin ve vatandaşların yararlandıkları faydalardan eşit yararlanma hakkı üzerine inşa edilmiştir. Kapsayıcı eğitim, eğitimin temel bir insan hakkı olduğu gerçeğinden yola çıkarak, hiçbir öğrencinin cinsiyet, engellilik, farklı bir ırk, din ya da etnik alt gruba mensup olmak, kent yoksulu olmak, cinsel yönelim ya da vatandaş olmamak (sığınmacı, mülteci, göçmen) gibi bir farklılığa ya da istisnai duruma dayalı olarak sistematik dışlanma pratiklerine maruz kalmaması için ortaya atılan bir kavramdır. Eşitlik kavramı, özellikle erişimde eşitlik olarak ele alındığında içkin durumlarından dolayı kalıcı bir şekilde eğitime erişimlerinde sorun yaşayanların engellenmesinden dolayı yeterli olmamış, bu nedenle erişimde eşitlik değil adaletli olmanın yolu olarak kapsayıcılık kavramı ortaya atılmıştır. 
Kapsayıcıllğın özünde yalnızca her türden ve her düzeyde farklılı̆̆ı olanı kapsamak vardır. Kapsanmanın tek şartının insan olmak olması ve kapsarken farklı ihtiyaçlardan dolayı farklı çevreler gerekiyorsa bunları ve diğer her türlü desteği koşulsuz ve insana saygıdan ötürü sağlamak ve böylece sadece farklı olana değil farklı olmayana da toplumsal kazanımlar sağlamak vardır (Altunoğlu, 2019). Kapsayıcı eğitim, UNESCO'nun 1994 tarihli Salamanca Bildirgesi'nde (UNESCO, 1994) de belirtildiği gibi, tüm düzeylerde eğitim kurumlarının ve sisteminin kız ya da erkek, etnik azınlık mensubu, hasta, engelli, göçmen, evsiz, gezgin ya da öğrenme güçlüğü yaşayan tüm bireylere destek olmak ve onların dahil olduğu toplumun da daha kapsayıc hale gelecek olmasindan sorumlu olmak anlamina gelmelidir (Slee, 2011).

Avrupa'da ilk olarak azınlık haklarının güvenceye alınmasını amaçlayan hükümlerin yer aldığı uluslararası düzeyde anlaşmalar türünde mekanizmalara I. Dünya Savaşı sonrasında sınırların yeniden şekillenmesi nedeniyle ihtiyaç duyulmuştur (Kaya, 2012). Kapsayıcılık bu mekanizmaların ve belgelerin çoğunun azınlıkların kamusal alandaki varlıklarını sürdürebilmeleri ile ilgili hususlar açısından yararlı olmakla birlikte diğer katılım ve ayrımcılık sorunları ile ilgili standartlara duyulan ihtiyaç nedeniyle önem kazanmıştır. Azınlık olarak adlandırılamayacak bu diğer farklılıkların kapsayıcılığın günümüzde geldiği nokta itibariyle içerdiği gruplar şu şekilde özetlenebilir: etnokültürel farklılıklar, cinsiyet ve cinsel yönelime dayalı farklılıklar, soyoekonomik ve sınıf farklılıkları ve farklı yapabilirlik kapasitelerinden dolayı engele sahip kabul edilenler (Kricke ve Neubert, 2017). Bunlarla mücadele edebilmek ve kapsayıcı olabilmek için eğitim kurumlarının ırkçılık karşıtlığı, cinsiyet ayrımcılığı ve homofobi karşıtlığı, sınıfçılık karşıtlığı ve engellilere yönelik ayrımcılık karşıtlı̆̆ ilkelerini benimsemesi beklenmektedir.

Yükseköğretimde kapsayıcılık genellikle bireylerin toplumla bütünleşmelerinden doğacak olumlu katkılar açısından daha çok, onların eğitim yaşantılarını sürdürebilmeleri üzerinden tartışılmaktadır (Collins, Azmat ve Rentschler, 2019). Bunun nedeni kapsayıcılık kavramının yalnızca engelliler üzerinden ele alınmasıdır ki yalnızca bir fiziksel ya da zihinsel engele sahip bireylerin yükseköğretimde kapsanmaları ya da dışlanmaları ile ilgili de çok az çalışma vardır (Collins, vd., 2019). Kapsayıcılığın kendisinin bile kapsayıcı bir kavram olmaktan uzak bir biçimde yalnuzca bir fiziksel ya da zihinsel farklılığa sahip bireyleri kastedecek biçimde kullanılması, bu bireylerle ilgili ayrımcllı̆̆ın nedenlerinin cinsiyet ya da etnisite gibi diğer dezavantajlı grup 
mensuplarının maruz kaldığı ayrımcılığa göre daha az politik kökenli olmasindan kaynaklanmaktadır (Dolmage, 2017). Postmodern anlamda bir kapsayıcı eğitim kavramı, sosyo kültürel kimlikler ve diğer her tür farklılık nedeniyle farklı eğitim ihtiyaçları olan bireylerin bir arada eğitim görmeleri için uygun ortamların, politikaların ve uygulamaların sağlanmasını öngören bir eğitim ilkesidir.

Dolayısıyla, kapsayıcılı̆̆ın ve kapsayıc eğitimin yöneticiler, öğrenciler ve öğreticilerin inanç ve anlam dünyalarına da erişebilmesi için tedbirler alınmalıdır. Nussbaum'un da vurguladığı üzere, tüm insanların eşit ve özgür olduğu ve devletin ve onun işlevlerinin buna göre düzenlenmesi gerektiğinden hareketle, bir toplumun engellilere, ya da diğer tüm dezavantajlı gruplara takındığı tavır onun adalet, eşitlik ve özgürlük anlayışını ortaya koyacaktır. Yani, toplumun dezavantajlı bireylerine karşı beslediği duygular bu bireylere yönelik uygulanan politikalardan ciddi bir biçimde etkilenmektedir. (Nussbaum, 2016, s. 211-213).

\section{Yükseköğretimde Kapsayıcılık}

Kapsayıclıkla ilgili en büyük yanılgılardan biri, kapsayıcılıktan söz edildiğinde dezavantajlı bireylerin fiziksel erişiminin ve eğitim malzemelerinden faydalanmalarının anlaşılmasıdır. Böylesi bir anlayıştan hareket edildiğinde, esasen dezavantajlı bireylerin başarılı olmaları değil sadece görünür olmaları beklenmektedir. Yükseköğretimde genellikle istisnai duruma sahip öğrenci yasal yükümlülüklerden dolayı kabul alır, ayrımcılıktan korunur; fakat başarıyla mezun olması yönünde bir destek sürecine dahil olamaz. Bu durum daha düşük sosyo-ekonomik arkaplana sahip bireyler için de geçerlidir. Oysa sosyal adalet kuramına göre engelli olan ya da olmayan kimseler ile, daha zayıf ekonomik ve toplumsal kaynaklara sahip kimseler de ortak kazançtan aynı şekilde yararlanmalıdırlar. Hiç kimse diğer bir kesimin daha iyi şartlarda eğitim alması için kurban edilemez (Rawls, 2017). Kapsayıcı bir eğitim kurumu, öğrencilerin her birinin birbirinden farklı gereksinimleri olduğunu bilip bunlara cevap verecek şekilde farklı öğrenme ortamları oluşturulmasını benimsemelidir. Buna göre dezavantaja ya da istisnai duruma sahip olanlar başta olmak üzere tüm öğrencilere uygun müfredat, kurumsal ve fiziki düzenlemeler ve öğretim stratejileri geliştirmeye açık ve bu konuda gayretli olmalıdır. 
Yükseköğretime erişime yönelik dezavantajların oluşmaması için, istisnai duruma sahip bireylerin eğitim kaynaklarına erişimi garanti altına alınmalıdır. Açıklık, e-öğrenme ve teknolojiyle güçlendirilmiş nitelikli öğrenme, ilk olarak katılım sorununda aşama kaydedildiği takdirde yükseköğretimin öğrenme açısından da kapsayıcı olabilmesi için kullanılabilecek bir takım araçlardır. Bundan hareketle bu bölümde bu kavramlara değinilecektir.

20. yüzyılın en önemli değişimlerinden biri olarak yükseköğretime olan toplumsal talebin ve katılımın büyük oranda artması gösterilebilir (Wolter, 2014). Bu hızlı büyüme ile birlikte, öğrenci kitlesini oluşturan kompozisyonun geldiği aile, yetenekler ve beklentiler açısından çok daha fazla 'çeşitlilik' içeren bir yapıya bürünmesinin sağlanacağı beklentisi oluşmuştur. Katılımın genişlemesi, toplumun daha önce yükseköğretimde az temsil edilmiş kesimlerinin dahil edilmesini kolaylaştırmış olsa da, pek çok ülkede bu genişleme ile öğrenci kitlesinin heterojenleşmesi arasında çok zayıf bir ilişki bulunmuştur (Eurostudent, 2012). Son Bologna süreci ilerleme raporunda da aynı şekilde düşük sosyo-ekonomik statüye sahip ailelerden gelen, göçmenlik geçmişi olan, kronik hastalıkları ya da engelleri olan öğrencilerin yükseköğretimde temsil düzeylerinin düşük olduğu doğrulanmaktadır (2018). Buna göre, cinsiyet dengesizlikleri de, özellikle bazı disiplinlerde, devam etmektedir. Raporda dikkat çekilen başka bir husus ise yükseköğretimi bırakma oranının özellikle temsil düzeyi düşük gruplar arasında daha yüksek olduğudur.

Burada öğrenci kitlesinin heterojen yapısına atıfla kullanılan çeşitlilik kavramının iki farklı teorik kökenden geldiğini hatırlamakta fayda vardır. İlki daha sosyo-politik bir köken olan insan hakları temelli sosyal adalet ve eşitlik fikri iken, ikincisi insan kaynaklarının çeşitliliğini bir yönetim stratejisi olarak gören ve insan sermayesi kuramında temellenen bir anlayıştır. Sosyal adalet ve eğitim hakkı çerçevesinde ayrımcılıklara karşı geliştirilmiş olan kapsayıc1lık kavramı ise çeşitliliğin ilk teorik kökenine yakın olduğu için iki kavram kimi zaman birlikte kullanılabilmektedir. Wolter (2014), çeşitlilik kavramının sosyal adalet ve fırsat eşitliği gibi daha politik çağrışımları olan kavramların yönetimsel bir yaklaşımla nötrleştirilmiş hali olarak dolaşıma girdiğini öne sürer. 
Yükseköğretimdeki genişlemenin tam olarak heterojenlikle sonuçlanmamış olması, pek çok üniversitenin bir endüstriyel örgüt özelliklerine benzer nitelikler taşıması ile ilgili olabilir (Gilbert, 2005). Dersler sabit zaman ve yerlerde tam zamanlı ve eksiksiz katılım beklentisi ile devam eder ve her öğrenciye aynı konu, aynı okuma listesi ve ödevler sunulur (Bates, 2010). Kapsayıcılık kavramı, yükseköğretimde mükemmellik arayışlarında bu nedenle önemli yer tutmal, yenilik çabalarının merkezinde öğrenme ve öğretme süreçlerinin kolaylaştırılması, kalıcılaştırılması ve toplumsal olarak anlamlı hale getirilmesi olmalıdır. Günlük hayatımızda 300 ya da 400 yıl önceden gelen bir zaman yolcusunun tanıamayacağı ya da anlamlandıramayacağı ne çok şey olduğunu düşünebiliriz; fakat yükseköğretimin ayrılmaz bir parçası gibi düşünmeye devam ettiğimiz arka arkaya onlarca sıranın sıralanmasıyla oluşmuş ve bildik sorulara bildik cevaplar aranan sınıflar bunlardan biri olmayacaktır (Cross, 2010).

Yükseköğretim özünde öğrenen öğreten, üniversite şehir, üniversite endüstri gibi pek çok düzlemde ilişkisel olan bir sektördür. Bu sosyal yönü nedeniyle olumlu sosyal ilişkiler ve bağların sağlıklı bir şekilde kurulması ve korunması yöneticiler için elzemdir. Aynı şekilde, bu ilişkilerin belli bir grubun avantajına olacak şekilde sürdürülmesine dayanan eylemler ne sürdürülebilirdir ne de etiktir (Kezar, DePaola, ve Scott, 2019). Bu ilişkilerin temelinde ekonomi olduğu görülse de, yükseköğretimin ekonomik ve toplumsal amacının sadece bir kesimin ya da sadece yararlananların değil tüm toplumun ekonomik ve toplumsal refahını artırmak olarak algılanması gerekmektedir. Toplumlar, daha büyük çerçevede sosyal adalete erişmek için çözmek zorunda olduğumuz pek çok problem için üst düzey uzmanlık bilgi ve becerisine ihtiyaç duymaktadır. Yükseköğretim bu bilgi ve beceriye ulaşma yollarını öğreterek sosyal adalete ulaşmada kritik bir rol üstlenir. Böylece toplumun tüm üyelerinin ekonomik ve toplumsal refahını artırma amacına hizmet eder (McArthur, 2013). Adorno başta olmak üzere, eleştirel teorinin birçok temsilcisi yükseköğretimin sosyal adaleti sağlamada ve aydınlanmadaki rolünü vurgulamışlardır (McArthur, 2013). Her ne kadar dünyayla karşılaştırıldığında Türkiye'de yükseköğretimde akademik kapitalizmden daha çok kamu yararı güdüldüğü gözlense de, nitelikli yükseköğretime ulaşmada yoğun rekabetten dolayı sosyo-ekonomik göstergelerin etkili olmaya başladığı 
söylenebilir. Kamu yararı gözeten bir misyona sahip olmasından dolayı üniversiteler herhangi bir politika şekillendirme sürecinde sosyal adalet ve sürdürülebilirlik ilkelerini tartışılmaz olarak kabul etmelidir (Boni vd., 2016).

Üniversite yönetimlerinin hem öğrencilerin hem de öğretim elemanlar1nın 'yüksek' düzeyde öğrenmelerini destekleyen araştırma ve öğretim merkezleri olma yönünde bir çaba yerine, kişisel ya da grup çkarları gözetilebilen alanlarda sıkışıp kaldığı gözlemlenmektedir. Çevrimiçi ya da yüz yüze, sinıfta ne olup bittiği, ne düzeyde bir öğrenme gerçekleştiği ve bunun toplum ve piyasa ihtiyaçlarına ne kadar uyumlu olduğu meselesi akademik özerklik olgusunun kültürel yerleşikliği nedeniyle genellikle arka planda kalmaktadır. Bağımsızlık ve değişen toplum ihtiyaçlarına uyumun bir arada olması üniversitelerin melez kurumlar olarak görülmesine neden olmuştur (Jongbloed, 2015). Yönetimsel ve finansal özerklik düzeylerinde ülkeden ülkeye değişiklikler görülen yükseköğretim kurumları, genel olarak ihtiyaç duyulan yenilikleri hayata geçirirken ya da değişime ayak uydururken topluma olan sorumlulukları ve akademik miras arasında denge kuracak bir biçimde akılcı bir şekilde yönetilmelidir. Bu yeniliklerin neler olduğunun ve hayata geçirilme düzeylerinin küresel düzeyde karşılaştırıldığı bir çalışmada, çevrimiçilik, açıklık, esneklik, kapsayıcılık ve teknolojiyle güçlendirilmişlik gibi yenilikler ortaya konmuştur (Orr, Weller ve Farrow, 2018).

Kabul sayıları büyük ölçüde artmış olsa da yükseköğretim kurumları arasındaki eşitsizliklerin yol aç九t̆̆ı standartlarda aşınmaya açık eğitim kaynakları bir çözüm olarak düşünülebilir. Yükseköğretime hiç dahil olmayanların da yükseköğretimin üretmek ve aktarmakla sorumlu olduğu bilgiden yararlanabilecekleri MOOC'lar (Massive Open Online Courses) bunun bir örneğidir. MOOC'ların açıklığı yalnızca ücretsiz olmaları değil, aynı zamanda dezavantajlı bireyleri de kapsayacak şekilde açı olmaları anlamına gelir (Acedo ve Osuna, 2016).

Açı eğitim kaynakları, eğitime yönelik hazırlanan içeriğin ücretsiz ve serbest olarak yeniden kullanıma açık olması anlamında kullanılmaktadır (Schaffert, 2010). UNESCO'nun düzenlediği Gelişmekte Olan Ülkelerde Yüksek Öğretimde Açık Eğitim Malzemelerinin Önemi Forumu'nda eğitim kaynaklarının ve bunları ileten bilgi ve iletişim teknolojilerinin danışma, uyarlama ve yeniden kullanıma parasız bir şekilde açık olması anlamında tartışımiştır (2002, s. 24). 
Açıklığın temelinde diğerkâmlık olduğu kadar kurumsal ve mali motivasyonlar da yatmaktadır (Sclater, 2010). Dahası, bilimle ve bilgiyle angaje olmanın önünde kamu için hala pek çok ciddi engel varken açık kaynak politikaları bunu gizlemeyi kolaylaştıran bir yanılsama olabilir (McArthur, 2011, s. 74). Orr, Rimini ve Van Damme (2015)'ın hazırladığı OECD raporu da açıklğın bedelsiz bilgi edinmek anlamına gelmekten çok bedelleri kimin ödediği ile ilgili bir düzenleme olduğunun altını çizer. Fakat yine de, yükseköğretimin daha kapsayıcı olması için açıklıktan yararlanılmalıdır.

Yükseköğretim kurumlarının ya aşırı yönetildiğini ya da yönetilemediğini ileri süren Ehlers ve Schneckenberg'e (2010) göre, bunun sonucunda yarının yöneticileri de iyi yetiştirilememektedir. Yükseköğretim halihazırda zaten dijitalleşmenin bize sunduğu yeni firsatlardan nasıl daha iyi yararlanacağını belirlemesi gereken bir yol ayrımındayken (Orr vd., 2018), pandemi nedeniyle zorunlu olarak gerçekleşen kısmi açıklık ve esnekliğin hedeflenen dijital dönüşümü ne ölçüde yansıttığı tartışmalıdır. Herhangi bir içeriğin dijitale çevrilip tek yönlü olacak şekilde öğrenciye sunulması, bahsedilen açıklık, kapsayıcılık, esneklik gibi hedeflerin gerçekleştirildiği anlamına gelmemektedir.

Kalite daima üniversitelerin gelecek planlamasının odağında olması gereken bir kavramdır. Genel olarak kalite olgusuna gelen eleştiriler arasında, gözetleme ve kontrol işlevinin baskın hale gelmesinin akademinin standartlaşma uğruna kontrol altına alınmasını doğuracağı endişesi dile getirilmiştir (Dill, 1997). Yükseköğretim kurumlarında kalitenin kontrol ve denetim işlevleriyle değil, bilim insanları ve öğrencilerin katılım yoluyla güçlendirilmesi ve daha yeni ve nitelikli eğitim öğretim ve araştırma faaliyetleri yürütülmesi için cesaretlendirilmesiyle öne çıması gerekmektedir (Ehlers ve Schneckenberg, 2010). Değişime ve krize hızlı bir biçimde uyum sağlama becerisi kolektif kapasite ile doğrudan ilişkilidir. Gelişme ve iyileşme yerine standartlaşma ve kontrol işlevlerinin öne çlkarılması yükseköğretimin kolektif kapasitesini olumsuz etkilemesi nedeniyle de Türk yükseköğretimi için üzerinde düşünülmesi gereken bir durumdur.

Bilgi ve iletişim teknolojilerindeki gelişmeler başta yükseköğretim olmak üzere tüm düzeylerde büyük değişimlere sebep olmuştur. Fakat bu değişimlerin etkisinin henüz beklenen düzeyde olmadığını söyleyebiliriz. Bunun nedeni, bazı yenilikler olsa da, öğrenme ve öğretme süreçlerindeki dönüşümün henüz tam olarak gerçekleşmemesidir. Yeni teknolojilerden yararlanma şu 
anda çoğunlukta eski bağlamlara yeni yöntemler iliştirme şeklinde uygulanmaktadır. Eğitimin günümüzde bu açıdan geleneksel bir modelden teknolojinin başat rol oynadığı bir modele doğru bir geçiş döneminde olduğu söylenebilir (WEF, 2008). Dolayısıyla dönüşüm henüz tam olarak gerçekleşmemiştir. Öğrencilerin dijitalliğin yerlisi, öğretim elemanlarının ise ağır aksak takip etmeye çalışanları olduğu yükseköğretim kurumlarında, 21. yüzyıl becerilerinin öğrenme içinde kullanılarak kazandırılması gerekirken, teknoloji yalnızca zamanın gerisinde kalmış eğitim paradigmalarına otomasyon ve kontrol kazandıracak bir biçimde kullanılmakta, neyin ve nasıl öğrenileceğini de değiştirmiş olduğu göz ardı edilmektedir. Günümüzde öğretim elemanları öğretim işlevine yönelik olarak, disiplinle ilgili bilgiyi evrensel sınırlar içerisinde öğrenciye aktaran alan uzmanları rolünde hizmet etmektedirler. Teknoloji kullanımı ve dijitalleşme ile tanışılmasına karşın, hala büyük ölçüde yalnızca eski stratejilerin yeni araçlarla uygulanması ve geleneksel sınıf deneyiminin bir öğrenme yönetim sistemi üzerinden yürütülmesi söz konusudur.

Teknolojiden yararlanan öğretim yöntemleri geliştirilebilmesi için yalnızca teknoloji bilgisi değil ayn zamanda teknoloji destekli öğretim ve program tasarımı anlayışı geliştirilmesi gerekmektedir (Bates, 2010). Oblinger, Oblinger ve Lippincott'ın (2005) in 'ağ nesli', Veen ve van Stalduinen' (2010) in 'Homozappiens' adını verdiği, günümüzde daha yaygın karşılık bulan bir tabirle Z Kuşağına ait olan öğrenci topluluğunun kendilerine özgü öğrenme ihtiyaçları ve stilleri olduğu açıktır. Dolayısıyla özellikle öğretim kalitesinin geliştirilmesi ile ilgili tüm adımlarda onların fikirlerinin alınacağı kapsayıcı bir kalite politikası geliştirme ve değerlendirme sürecine dâhil olmaları gerekmektedir. Eğitim içeriği ya da yöntemlerinin kalitesinin geliştirilmesine yönelik bir örnek olarak Açıköğretim Fakültesi bünyesinde hayata geçirilen "Kalite Elçileri" projesi örnek gösterilebilir. Bu proje ile Açıöğretim Sisteminde üretilen öğrenme malzemeleriyle ilgili öğrencilerin fikirlerini ve değerlendirmelerini dikkate alarak Açıöğretim Fakültesi öğrenme yönetim sisteminde sunulan öğrenme malzemelerinin niteliğini artırmak amaçlanmıştır (Bozkurt, Büyük, Kılınç ve Özdamar, 2017).

Üniversitelerde araştırma rakamlarını geliştirmek için atılan adımlar ya da getirilen yeniliklerin yanında, aynı önemle öğrenme ve öğretme süreçleriyle ilgili yenilik adımları da atılmalıdır. Bu konu genelde yapıldığı gibi öğretim elemanlarının inisiyatifine bırakılmamalı; hem bireysel hem de kurum- 
sal boyutta etkileşimler yoluyla bir 'öğrenme kültürü' geliştirmek için harekete geçilmelidir (Euler, 2010). Araştırma faaliyetlerinde yenilikçi olmak beklenirken, öğrenme ve öğretme süreçlerinde geleneğe yaslanmak daha sıklıkla görülmektedir. Yenilikten bahsedilen nadir durumlarda ise kastedilen, içeriğin yenilenmesi ya da güncellenmesi olmakta, öğrenme süreçlerinin yeni nesille birlikte nasıl değiştiği konusu daha az ilgi görmektedir.

Çeşitli demografik özellikleriyle, farklı öğrenme stilleriyle, farklı alışkanlıkları ile ve artan sayıda yükseköğretime katılan öğrencilerin farklı öğrenme ihtiyaçlarına nitelikli öğrenme kazanımları ile cevap verebilmek, öğretim elemanları için en ciddi zorluklardan biri olmakla birlikte, bu konu bir hak ve kapsayıcılık meselesi olarak ele alınmadığından, bu zorluğa karşı bir eylemsizlik mevcuttur (Feixas ve Zellweger, 2010). Bu eylemsizliği aşmak için kapsayıcılığa öğrenme kültürlerini de içine alacak şekilde bakılarak, farklı öğrenme tercih ya da becerilerinin de farklılık olarak kabul edilip onlara karşı duyarlı bir öğrenme deneyimi inşa edilebilmesinin yolları aranmalıdır. Eleştirel ve yansıtıcı düşünmeyi geliştiren, katılıma ve diyaloga dayalı öğretim yöntemleriyle birlikte öğretim programlarının da sınıflardaki kültürel ve çokkültürlü yapıyı ve küresel sorunları da ele alan bir yapıya bürünmesi yükseköğretimin insani ve toplumsal gelişim rolünü gerçekleştirmesi için şarttır.

Öğrenenlerin soru sormaktan çekinmedikleri ve öğretenlerin de onların sorularını dinlemeye ve uygun cevaplar sunmaya yetecek zaman kaynağına sahip oldukları bir etkileşim ortamı öğrenenlerin soyut kavramlar ve içerik ile gerçek hayat deneyimleri arasında bağ kurabilmeleri için son derece önemlidir. Öğretim elemanının öğrenciye ayırdığı bire bir zamanın ve aradaki etkileşimin niceliği ve niteliğinin öğrenci başarısını olumlu etkilediğini gösteren çok sayıda çalışma yapılmıştır (Kezar, DePaola, ve Scott, 2019). Son yıllarda öğrenci kabul sayılarının ciddi düzeyde artmış olması bu konuda sıkıntıların yaşanmasına neden olmaktadır. Kabul sayılarındaki artma eğiliminin bir başka sonucu da kabul alan öğrenci niteliğindeki düşüşe bağlı olarak içeriğin kolaylaştırılması yukarıda bahsedilen sosyal adalet amacına yönelik bilgi ediniminin de daha az yararlı olması sonucunu doğuracaktır.

Sosyal adalet teorisi üniversite için işgücü piyasasına yönelik insan kaynağ 1 yetiştirmekten öte, ekonomiyle birlikte toplumu da ilgilendiren bir misyon biçmiştir. Bu misyon demokratik bir toplumun sürdürülebilmesi için insan refahını, eşitlik ve adaleti sağlama olarak özetlenebilir (Walker ve Boni, 2013). Bu misyonun gerçekleşmesi için gereken bilgi, 'nelik' üzerinden değil 
'neden-sonuç' üzerinden giderek, olanı edilgen bir biçimde kabul etmek yerine statükonun ötesinde kapılar açabilmeleri için öğrencilere fırsatlar sunan türden bir bilgidir (McArthur, 2011). Dolayısıyla yükseköğretim hem disipliner bilginin gerekliliklerini karşılamalı hem de varsayımlarını sarsıp sınırlarını zorlamalıdır (Rowland, 2006, s. 39).

Baker, Bujak ve DeMillo (2012, s. 331) yüksek öğretimin en az 3 cephesinde bir değişimin gerekliliğini iddia etmiştir. Bunlar sınıf ve sınıf ötesinde kullanılacak teknolojiler, öğrenenlerin ve öğretenlerin gerekli teknolojileri edinebilmeleri için pratikler ve süreçler gerçekleşmesi ve bu süreçlerin yürütüleceği kurumsal değişim ve yenilik çabaları olacaktır. Bu teknolojilerin başında e-öğrenme gelmektedir. Aslına bakılırsa Covid19 sürecindeki deneyimlere kadar e-öğrenme pek çok ülkede hala örgün eğitimi takip edemeyen öğrenciler için bir 'ikinci şans' gibi (Ghislandi, Raffaghelli ve Yang, 2013) algılanmaktaydı. Günümüz öğrencileri e-öğrenmeyi mümkün kılan çevrimiçi ortamlara doğal olarak yatkın olmalarını sağlayacak türden deneyimlere sahip olsa da, üniversite sisteminin durağan ve değişime kapalı yapısı nedeniyle eöğrenme örgün ya da uzaktan tüm yükseköğretimin vazgeçilmez bir değeri haline gelememiştir. Yükseköğretimde yeni dönemde e-öğrenmeyi güçlendirecek kalite politikaları üzerinde düşünülmesi ve e-öğrenme için şart olan dijital yeterliklere yaşamboyu öğrenme bağlamında odaklanılması gerekmektedir (Ghislandi vd., 2013). E-öğrenmenin sağlayacağı dijital yeterlikler bireye yeni nitelikler ve yeni iş firsatları kazandırırken, bundan sonraki dönemde eöğrenme üzerinden gelişme gösterecek olan yaşamboyu öğrenmenin de temelini oluşturmaktadır.

Açık ve uzaktan öğrenme, özellikle gelişmekte olan ülkelerde, yükseköğretime devamın önündeki cinsiyete, yaşa, sosyo-ekonomik statüye, coğrafi uzaklığa ya da başka istisnai durumlara dayalı bireysel ve toplumsal engelleri ortadan kaldırarak kapsayıcılık düzeyini geliştirmede son derece yararlı olmuştur (Yasmin, 2013). Açık ve uzaktan öğrenme aracılığıyla yükseköğretime devam konusunda dijital dönüşüm sayesinde büyük mesafe kat edilmiş olsa da, eğitimi bırakma sorununun kapsayıcılık konusundaki kazanımlara zarar vermesine izin verilmemelidir. Bırakma ile ilgili yapılan çalışmalar, genellikle öğrencinin kampüse uzak bir biçimde öğrenmesini aile, iş ve diğer toplumsal yükümlülükleri arasına entegre etmede yaşanan zorluklardan kaynaklandığını, bunun da cinsiyet ve gelir düzeyi gibi bireysel farklılıklara göre değişkenlik gösterdiğini öne sürmüştür (Kember, 1989). Kadınların iş 
yaşamında temsil düzeylerinin erkeklere göre düşük olduğu ülkemizde, eğitim düzeyi arttıkça bu farkın kapandığı gözlemlenmiştir (Dayığlu ve Kırdar, 2019). Dolayısıyla kadının yükseköğretime hem katılımının hem de başarısının önündeki engellerle mücadele etmek için desteklenmesi kadının istihdama katılımı konusunda da fayda sağlayacaktır. Mevcut haliyle kadınların yükseköğretimde temsiline bakıldığında Türkiye \% 45 ile Avrupa Yükseköğretim Alanı ülkeleri arasında en düşük orana sahiptir. Dahası bu oran lisansüstü eğitimde ve belli çalışma alanlarında daha da düşmektedir (Eurostudent VI, 2018).

Diğer bir bireysel farklılık olarak karşımıza çıkan düşük sosyo-ekonomik düzeye mensup olmanın yükseköğretimde başarıyı etkileyen faktörlerden biri olduğu söylenebilir (Quinn, 2013). Eurostudent VI araştırmasının sonuçlarına göre anne ve babası yükseköğretime dahil olmamışöğrenciler hala pek çok ülkede düşük düzeyde temsil edilmektedirler (2018).

Bırakma ile ilgili daha sonra yapılan çalışmalar ise devam edilen eğitimle ilgili tatmin düzeyi ve devam ettiği kurumdan gördüğü destek gibi faktörlerin de bırakma kararında etkili olduğunu ortaya koymuştur (Park ve Choi, 2009). Dolayısıyla, hem örgün hem de açık ve uzaktan öğrenme uygulayan yükseköğretim kurumlarının kapsayıcılı̆̆ı sürdürebilmeleri için özellikle risk grubundaki öğrenciler için kurumsal destek ve öğrenci gelişiminde bire bir rehberlik gibi uygulamaları hayata geçirmeleri gerekmektedir. Kapsayıcılık yalnızca yükseköğretim fırsatı sunarak değil o firsatın değerlendirilmesinde yaşanan sorunların çözümüne rehberlik eden ve öğrenciyi sadece kayıt yaptırmaya değil ayn zamanda mezun olmaya da motive eden bir süreçte yürütülmelidir.

Conole (2012) tarafından 'görünmeyeni görünür kılma' yani etkili öğrenme ile sonuçlanacak içerikler, ortamlar ve kaynakların üretimi ve dağıtımı olarak tanımlanan 'öğrenme tasarımı' kavramı önem kazanmalı ve katılım odaklı kalite çalışmalarının temelini oluşturmalıdır. Bireyde bir yansıması olmayan öğrenme, öğrenme sayılmayacağından (Cross, 2010), herkesin kendi kendinin öğrenme tasarımcısı olması gereken bir döneme girmekteyiz. Bunun yapılabilmesi için, yükseköğretimde teknolojilerin bize sunduğu potansiyelin gerçekte ne ölçüde kullanıldığı ve ne düzeyde bir öğrenme ile sonuçlandığını dikkate alan bir anlayışa ihtiyaç vardır. Katılım söylemi öğrencinin bir dersin içeriğini gerçek anlamda hayatının içine nasıl entegre ettiğini pek dikkate almamaktadır (Fielding, 2016). Bu nedenle, özellikle açık ve 
uzaktan öğrenmede öğrencilerin içeriği hayatlarındaki deneyimlerin, zamanlarının, enerjilerinin ve toplumsal yükümlülüklerinin neresine oturtacakları hakkında daha kapsayıcı bir şekilde düşünülmesine ihtiyaç vardır. Çevrimiçi öğrenmenin yükseköğretime katılımı vaat ettiği, öğrencilere özerklik ve özdisiplin kazandırdığ1 ve özellikle çalışan öğrenciler için bir fırsat olduğu doğru olmakla beraber, öğrenenlerin bu 'herhangi bir yerde ve herhangi bir zaman' mitini geçerli hale getirmek için özel hayatlarında nasıl bir yerleştirme yaptıklarının da hesaba katılması anlamlı olacaktır. Fielding'in (2016) çalışmasında birlikte paylaşılan bir zaman dilimi olduğunda 'herhangi bir zamanın' varlık bulmasının hem daha kolay olduğu hem de öğrencileri birbirine sosyal olarak da bağlayarak bir öğrenme topluluğu oluşmasına katkı sağladığ1 sonucuna varılmıştır. Daha sosyal bir öğrenme ortamı yaratılması için bire bir danışmanlık desteğinin hem örgün hem de uzaktan eğitimde güçlendirilmesinin kapsayıclık yönünde önemli bir adım olacağı öngörülmektedir (Chatterjee ve Moore, 2009). Bire bir danışmanlı̆ın örgün yükseköğretimde de yüz yüze yerine çevrimiçi oalrak uygulanması, özellikle çalışan öğrenciler dikkate alındığında, kapsayıcılık kapasitesini artırıcı bir önlem olarak düşünülebilir.

Katılımın ne kadar öğrenme ile sonuçlandığı meselesine dair 2019/2020 akademik yılı bahar dönemi itibariyle kendimizi içinde bulduğumuz pandemi sürecinden öğreneceklerimiz olsun diye bu konuda kısa zamanda dünyada ve Türkiye'de pek çok çalışma yapılmıştır. Bu ilginin başlıca nedeni eğitimin bu durumdan en çok etkilenen toplumsal alanlardan biri olmasıdır (UNESCO, 2020).

\section{Pandemi Sürecinde Uzaktan Eğitim}

Covid19 koruma tedbirleri kapsamında yüz yüze eğitimin durdurulmasının ardından eğitimin devam edebilmesi için çevrimiçi ortamların kullanılması uzaktan eğitim kavramının öneminin anlaşılmasına katkı sağlamıştır. 'Eğitim uzaktan olmaz' önyargısına sahip olan kişilere bu olguyu öğrenci ya da öğretici olarak deneyimleme ve avantaj ve dezavantajlarını değerlendirme firsatı sunmuştur. Sarıtaş ve Barutçu'nun (2020) çalışması çevrimiçi öğretime hazır bulunuşluk ile daha önceden çevrimiçi herhangi bir eğitim alma arasında olumlu yönde bir ilişki olduğunu ortaya koymuş; çevrimiçi öğrenim 
uygulamalarını deneyerek/yaşayarak bu mecraların benimsenip, kabullenildiği ve daha kolay yönetilebildiğini göstermiştir.

Aynı zamanda, eğitim için söz konusu olan eşitsizlikler çevrimiçi ve dijital ortamlarda da kendini göstermeye devam etmiş, internet olanağ 1 olmayan ya da kişisel bilgisayara sahip olmayan az sayıda öğrencinin yanı sıra çevrimiçi pratiklere ilişkin deneyimi az olan öğretim elemanlarını da zorlamıştır. Dünya nüfusunun \% 93'ünün coğrafi olarak internet erişimi olmasına rağmen internet kullanımı oranının \% 53 olması (Uluslararası Telekomünikasyon Birliği, 2019), dünyanın daha az gelişmiş kısımlarında dijital uçuruma neden olan faktörün erişimden daha çok internet kullanım ve cihaz ücretleri olduğunu göstermektedir. Tedbirler kapsamında Türkiye'de yükseköğretim öğrencilerinin hızlı bir şekilde yer değiştirmiş olmaları da öğrencilerin bazılarının internet aboneliğine sahip oldukları yerleşik düzenlerinden, aboneliğ $\mathrm{i}$ olmayan aile evlerine gitmeleri ya da sürecin uzayacağını tahmin edemeyip bilgisayarlarını bile almadan gitmiş olmalarıyla sonuçlanmıştır. Bu da öğrenme malzemelerine erişimde ve katılımda sorun yaşamalarına neden olmuştur. ABD'nin bazı eyaletleri ve Filipinler gibi bazı ülkelerde de eşitsizliğe neden olacağı gerekçesiyle uzaktan eğitimle devam edilmesi tedbiri hiç uygulanmamıştır (Eder, 2020). Her iki durumda, uygulanabildiği pek çok yerde dijital uçurum nedeniyle zaten dezavantajlı bir duruma sahip bireyler için ne kadar kapsayıcı olduğu, öğrenenlerin gerçek yaşam deneyimlerine dayalı olarak incelenmeli ve bundan hareketle genel olarak öğrenme süreçlerinin kapsayıcılık sorunları ile ilgili bir tartışma yapılmalıdır.

Bu süreçte aynı ilk ve orta öğretimde olduğu gibi TV benzeri daha kitlesel kullanılan iletişim araçlarının da işe koyulması, kitlesel medyanın planlama ve üretim aşamaları için çok daha fazla zamana ihtiyaç duyması nedeniyle, yükseköğretimin çok çeşitli içeriği ve çok çeşitli ihtiyaçlara sahip öğrenci kitlesi için uygun olmamıştır (Eder, 2020). Türkiye' deki yükseköğretim kurumları açısından alınacak ders, kapsayıcılık açısından daha hazırlıklı olmaları ve genel sistemdeki eşitsizliklerin böylesi kriz dönemlerinde derinleşmemesi için programlarını ve politikalarını gözden geçirmeleri gerektiğidir. Örneğin, Telli Yamamato ve Altun'un çalışmasına göre, engelli öğrencilere ve eğitmenlere yönelik uygulama ve düzenlemelerin henüz çok sınırlı olması nedeniyle çevrimiçi eğitim sistemlerinin özellikle Covid19 döneminde engelli öğrencileri kapsayabildiği söylenemez (2020). Bunun temel nedeni her dezavantajlı bireyin farklı yapabilirlik kapasitesine göre kullanımına hazır yeterli sayıda 
çevrimiçi çoklu ortama dayalı öğrenme malzemesi olmamasıdır. Mevcut olanların da farklı yapabilirlikleri nedeniyle farklı öğrenme ihtiyaçlarına sahip bireylerin öğrenmesinde ne kadar etkili ve kapsayıcı olduğuna dair yapılmış yeterince çalışma yoktur.

Birçok üniversitede öğrenmenin sosyal yönü göz ardı edilerek yalnızca içerik ve ödev yüklemesi şeklinde gerçekleşen pandemi dönemi uzaktan eğitimi konusunda üniversitelerin değişen yeterlilikleri, teknolojik altyapının yetersizliğinden çok öğretim elemanlarının uzaktan eğitimle ilgili hazırbulunuşluğu ve üniversite yönetimlerinin dijital liderlik düzeyleri tarafından belirlenmiştir (Karadağ ve Yücel, 2020). Nitekim, Karadağ ve Yücel'in (2020, s. 9) çalışmasında "bünyesinde uzaktan eğitim veya Açıköğretim fakültesi bulunan üniversitenin öğrencilerinin" yalnızca 'teknik altyapı' faktöründe memnuniyet ortalamaları daha yüksek bulunmuş, diğer faktörler için anlamlı bir fark saptanmamıştır.

Asenkron çevrimiçi uygulamaların yanında video-konferans ya da canlı ders gibi senkron uygulamaların da mutlaka kullanılmasının bir öğrenme topluluğu yaratarak sosyal öğrenmeye katkı sağladığı ortaya konmuştur (Speece, 2012). Bunların kullanılmadığı üniversitelerde farklı yapabilirlik kapasiteleri ya da kültürel açıdan farklı öğrenme gereksinimleri olan öğrenenlerin öğrenme deneyimi daha da zor hale gelmiştir. Karadağ ve Yücel'in (2020) öğrencilerin yalnızca \% 22'sinin uzaktan eğitimde kullanılan içeriğin öğreticilik düzeyinden memnun oldukları yönündeki bulgusu bunu desteklemektedir.

\section{Sonuç yerine}

Yükseköğretime kabul alan öğrencilerinin büyük bölümünün yüksek motivasyona ve özdisipline sahip, kendi öğrenmesinden sorumlu bireyler olduğu fikri günümüzde büyük ölçüde geçerliliğini yitirmiştir. Bugünün öğrencileri çok daha çeşitli sosyo-ekonomik düzeyde ailelerden, farklı coğrafyalardan, kültürlerden ve hatta okuduğunu anlama düzeylerinden gelmektedir.

Dezavantajlı bir birey başarılı olduğunda, başarısından ötürü yüceltilmesi, söz konusu başarının istisnai bir durum olarak algılandığını gösteren toplumsal bir tutumdur. Yükseköğretim kurumlarının bu toplumsal tutumdan uzaklaşıp kapsayıcıllğı yalnızca erişim düzeyinde değil, her bireyin kendine özgü farklılıkları ile başarılı olma hakkı olarak görmeleri gerekmektedir. 
Aksi halde dik merdivenlere sonradan eklenmiş rampalardan farksız bir kapsayıcılık anlayışının hakim olduğu kanısına varılabilir. Bu anlamda teknolojinin getirdiği imkanlardan öğrenenleri birbirleriyle ve öğreticilerle bir araya getiren sosyal öğrenme toplulukları yaratmak için yararlanılırsa (Lu, 2016), bu topluluklarda farklılıklara karşı bir kültürel farkındalık ve karşılıklı anlayış toplumsal etkileşimler, fikir alışverişi ve işbirlikli öğrenme yoluyla kendiliğinden oluşacaktır. Dahası, yükseköğretimin başta gelen işlevlerinden biri olan istihdama hazırlama doğrultusunda, istisnai duruma sahip bireylere yönelik kapsayıcı tutumun eğitimden sonraki iş yaşamında da sürmesi için hem toplumun dönüştürülmesi hem de bireylerin güçlendirilmesi yönünde sorumluluk üstlenilmelidir. Toplumun farklılıkları sorun değil fayda olarak görmesi için öncelikle akademinin farklı olana ya da kendinden olmayana bakışını gözden geçirmesi gerekmektedir.

Kapsayıc yükseköğretimin, UNESCO'nun vurguladığı topluma tam olarak katılım amacına yönelik olarak gerçekleşmesi için, tüm bireylerin yükseköğretimde hem katılım hem de öğrenme çıktılarını eşit olarak edinme şanslarını kullanabilecekleri bir şekilde tasarlanması gerekmektedir. Küresel yönetişimin ürünü olan çabalar bu yönde olsa da, kurumsal düzlemde bakıld1ğında, kapsayıcılık pek çok kez yalnızca bedensel yapabilirlik kapasitelerindeki farklılıklardan ötürü farklı öğrenme becerilerine sahip olan ve farklı öğrenme malzemeleri ve süreçlerine ihtiyaç duyanlar açısından ele alınmaktadır. Bu nedenle, yalnızca engellilere yönelik ele alınan, katılımın önündeki engelleri yasal ve fiziki olarak kaldırmak olarak algılanan ve öğrenme süreçlerine odaklanmadığı için bireysel farklılığa sahip bireylerin başarılı olma şansına destek olmayan bir kapsayıcılık anlayışı yerine, kapsayıcılığa da daha kapsayıcı bir biçimde bakan bir anlayışa ihtiyaç vardır. 


\title{
EXTENDED ABSTRACT
}

\section{Applicability of Inclusiveness in Higher Education}

\author{
Asu Altunoğlu \\ Anadolu University
}

While participation in higher education has been expanding throughout the world, the mission of higher education that aims to enhance social justice and welfare for all in the society has gained significance, which resulted in the fact that it has become a more important actor globally. The expansion of participation, though, has not exactly caused a real heterogeneity in the student composition especially in terms of learning outcomes. The concept of inclusiveness was created with the ideal in mind to enhance the heterogenic quality of the widened participation in a way that is more diverse, pluralistic and multi-cultural as there are still issues of equality and discrimination in higher education. This study aims to contribute to these discussions with an emphasis on learning cultures and learning communities, through opening paths of thought on how online learning or open and distance learning may increase inclusiveness in higher education. It appears that the literature on inclusiveness has mostly focused on the differences between the physical and mental capabilities of individuals, which needs to be changed.

Inclusiveness is built upon the right of all individuals in the social and political community to be at equal distance from each other and the right to equally benefit from the advantages that all citizens are entitled to. Inclusiveness is related to access to power and public and private resources, and aims to improve the way society views marginalized group members. Inclusiveness may only be realized when socially and politically marginalized groups of today and the past feel valued, when their differences are respected, and when basic and fundamental needs and rights are met and recognized as much as those of dominant groups of the same society are met and recognized. The world has made significant progress in the closing the global gap in educational access. However, there are still inequalities especially when it comes to individuals with various socially, politically or culturally exceptional positions. The extent of inequality gets even more significant when ed- 
ucational attainment is taken into account as the presentation of disadvantaged individuals in higher education does not in a real sense support their learning experiences and thus achievements.

The theoretical roots of inclusiveness are based on social justice and equity in education as education is considered a founding component of society. Participation and access to educational rights and benefits is what inclusiveness has mostly been about in terms of higher education. As universities are widening access to a greater number of students, diversity of all kinds increases. Open and distance learning technologies are an asset that we have today in terms of Turkish higher education that we can use to bring people together as a community and create contexts where quality learning outcomes for a greater number of students are enhanced. Quality learning outcomes can be built through cultural awareness and understanding that are developed by the newly formed learning communities in faculty culture. The challenge for faculty today both in the world and in Turkish higher education is to cater for the diversity of students' learning needs.

The discourse of universal access usually ignores the processes by which students integrate the course into their specific lives. We need to engage the difficulties and costs of making both online and regular courses work in students' lives as they have a very differing needs caused by socio-economic identities. They might be going through a struggle to figure out when they will complete work for their course, together with other demands on their time and energies, and what relationship it has to the other parts of their experience.

Online education has given us many opportunities in increasing universal access to higher education especially for disadvantaged members of the society through giving them autonomy of time and place. However, this paper claims that the autonomy of time and lace is not enough in itself to render higher education inclusive if it does not build opportunities for students to give them both autonomy over their learning and still help them feel connected to a learning community. The notion of a learning community is to create an environment for cultural inclusiveness that emphasizes on learning as social and interactive, involving interchange of ideas, shared inquiry and peer learning, and collaborative dialogue. 
Universities should strive for continuous efforts for innovations on giving the students a space of existence in a shared sense of time so that feel connected to each other and to see their individual crises as part of a broader social condition. Students are learning individuals, with a need for belonging to a community that we feel is better than other groups. The Covid-19 process that we have gone through for one academic semester yet has shown that this need is not something that could be neglected as otherwise no learning occurs. Open and distance learning could provide us with many opportunities in this direction, depending on the degree of an understanding of inclusiveness from a digital perspective. Not only digital infrastructure and literacy but also digital inclusiveness should be given greater emphasis in discussions of higher education expansion, with a special focus on learning cultures and learning communities.

\section{Kaynakça / References}

Acedo, S. O., and Osuna, S. M. T. (2016). ECO European project: inclusive education through accessible MOOCs. In Proceedings of the Fourth International Conference on Technological Ecosystems for Enhancing Multiculturality (p. 881-886).

Allan, J., and Slee, R. (2008). Doing inclusive education research (Vol. 1). Rotterdam: Sense Publishers.

Altunoğlu, A. (2019). Kapsayıcı eğitim kavramının felsefi, sosyolojik ve psikolojik temelleri. Kuramdan Uygulamaya Kapsayıcı Eğitim (der. P. Oya Taneri ) içinde. Pegem: Ankara.

Baker, P. M., Bujak, K. R., and DeMillo, R. (2012). The evolving university: Disruptive change and institutional innovation. Procedia Computer Science, 14, 330-335.

Banks, J. A. (Ed.). (1996). Multicultural education, transformative knowledge, and action: Historical and contemporary perspectives. New York: Teachers College Press.

Bates, T. (2010). New challenges for universities: Why they must change. In Changing cultures in higher education edited by D. Schneckenberg and U. D. Ehlers, (p. 15-25). Springer: Berlin, Heidelberg. 
Bologna Process Implementation Report (2018). Publications office of the EU. 15 Mayss 2020 tarihinde https://op.europa.eu/en/publication-detail/-/publication/2fe152b6-5efe-11e8-ab9c-01aa75ed71a1/languageen?WT.mc id=Selectedpublications\&WT.ria $\mathrm{c}=677 \& W T$.ria $\mathrm{f}=706 \& W T$.ria $\mathrm{ev}=\mathrm{search} \quad$ adresinden erişilmiştir.

Boni, A., and Walker, M. (Eds.). (2013). Human development and capabilities: Re-imagining the university of the twenty-first century. Routledge.

Boni, A., Lopez-Fogues, A., and Walker, M. (2016). Higher education and the post-2015 agenda: A contribution from the human development approach. Journal of Global Ethics, 12(1), 17-28.

Bozkurt, A., Büyük, K., Kılınç, H., ve Özdamar, N. (2017). Kitlesel kaynak kullanımı ve yaşamboyu öğrenenler: Açıöğretim Fakültesi kalite elçileri örneği. eğitimde fatih projesi eğitim teknolojileri zirvesi 2017 (s.58-62), 17-18 Ekim. Yenilik ve Eğitim Teknolojileri Genel Müdürlügü: Ankara.

Carlson, D., and Apple, M. (Eds.). (1998). Power, knowledge, pedagogy: The meaning of democratic education in unsettling times. Colorado, CO: Westview Press.

Chatterjee, M., and Moore, P. (2009). Issues of inclusivity for online distance learners: an academic learning support perspective.

Collins, A., Azmat, F., and Rentschler, R. (2019). 'Bringing everyone on the same journey': revisiting inclusion in higher education. Studies in Higher Education, 44(8), 1475-1487.

Conole, G. (2012). Designing for learning in an open world. London, UK: Springer.

Cross J. (2010). They had People Called Professors...! Changing Worlds of Learning: Strengthening Informal Learning in Formal Institutions. In: Ehlers UD., Schneckenberg D. (eds) Changing Cultures in Higher Education. Springer: Berlin, Heidelberg.

Dayığlu, M., and Kırdar, M. G. (2019). Determinants of and trends in labor force participation of Women in Turkey (No. 2019/02). Boğaziçi University, Department of Economics.

Dewey, J. (1976). Individuality, equality, and superiority. In J. A. Boydston (Ed.), John Dewey: The middle works, 1899-1924, Vol. 13 (p. 295-300). Carbondale, IL: Southern Illinois University Press.

Dill, D. D. (1997). Accreditation, assessment, anarchy? The evolution of academic quality assurance policies in the United States. In J. Brennan, P. de Vries ve R. Williams (eds), Standards and quality in higher education (p. 15-43). London and Bristol: Jessica Kingsley Publishers. 
Dolmage, J. T. (2017). Academic ableism: Disability and higher education. University of Michigan Press.

Eder, R. (2020). The remoteness of remote learning. Journal of Interdisciplinary Studies in Education, 9(1), 168-171.

Ehlers, U. D., and Schneckenberg, D. (Eds.). (2010). Changing cultures in higher education: Moving ahead to future learning. edited by D. Schneckenberg and U. D. Ehlers, Springer Science \& Business Media.

Etzkowitz, H. and Kloftsen, M. (2005) The innovation region: Towards a theory of knowledge based regional development, RED Management, 35(3).

Euler, D. (2010). Shaping learning cultures: A strategic challenge for universities. In Changing cultures in higher education edited by D. Schneckenberg and U. D. Ehlers (p. 75-84). Springer, Berlin, Heidelberg.

Eurostudent (2012). Annual Report. 15 May1s 2020 tarihinde https:/www.eurostudent.eu/download_files/documents/QA_Report_WP6_240212.pdf adresinden erişilmiştir.

EuroStudent (2018). Overview and selected findings. 15 May1s 2020 tarihinde https://www.eurostudent.eu/download_files/documents/EUROSTUDENT_VI_short_report.pdf adresinden erişilmiştir.

Feixas, M., and F. Zellweger. 2010. Faculty development in context: Changing learning cultures in higher education. In Changing Cultures in Higher Education, edited by D. Schneckenberg and U. D. Ehlers, 85-102. Heidelberg: Springer.

Fielding, H. (2016). Any time, any place: The myth of universal access and the semiprivate space of online education. Computers and Composition, 40, 103-114.

Ghislandi, P., Raffaghelli, J., and Yang, N. (2013). Mediated quality: an approach for the eLearning quality in higher education. International Journal of Digital Literacy and Digital Competence (IJDLDC), 4(1), 56-73.

Gilbert, J. (2005). Catching the knowledge wave? The knowledge society and the future of education. Wellington, New Zealand: New Zealand Council for Educational Research.

International Telecommunication Union - ITU. (2019). Measuring the Information Society Report 2019-Volume 1. Mayis 15, 2020 tarihinde https://www.itu.int/en/ITU-D/Statistics/Documents/publications/misr2019/MISR-2019-Vol-1-E.pdf adresinden erişilmiştir. 
Jongbloed, B. (2015). Universities as hybrid organizations: Trends, drivers, and challenges for the European university. International Studies of Management E Organization, 45(3), 207-225.

Kant, I. (2002). Ahlak metafiziğinin temellendirilmesi Çev. I. Kuçuradi, Ankara: Türkiye Felsefe Kurumu Yayınları.

Karadağ, E., ve Yücel, C. (2020). Yeni tip Koronavirüs pandemisi döneminde üniversitelerde uzaktan eğitim: Lisans öğrencileri kapsamında bir değerlendirme çalışması. Yükseköğretim Dergisi, doi:10.2399/yod.20.730688

Kaya, N. (2012). Türkiye'nin eğitim sisteminde azınlıklar ve ayrımcılık: Kavramsal çerçeve ve temel sorunlar. K. Çayır ve MA Ceyhan (der.), Ayrımcılık: Çok Boyutlu Yaklaşımlar, İstanbul: İstanbul Bilgi Üniversitesi Yayınları.

Kember, D. (1989). A longitudinal-process model of drop-out from distance education. The Journal of Higher Education, 60(3), 278-301.

Kezar, A., DePaola, T., and Scott, D. T. (2019). The gig academy: Mapping labor in the neoliberal university. Johns Hopkins University Press.

Kricke, M., and Neubert, S. (2017). Inclusive education as a democratic challenge-ambivalences of communities in Contexts of Power. Education Sciences, 7(1), 12.

Lu, H. (2016). Cultural Inclusiveness in Online Learning: Can Educational Technology Be a Solution? International Journal of Culture and History, 2(4).

McArthur, J. (2011). Reconsidering the social and economic purposes of higher education. Higher Education Research \& Development, 30(6), 737-749.

McArthur, J. (2013). Rethinking knowledge within higher education: Adorno and social justice. A\&C Black.

Nussbaum, M. (2006). Frontiers of justice: Disability, nationality, species membership. Cambridge, MA: The Belknap Press of Harvard University Press.

Oblinger, D., Oblinger, J. L., and Lippincott, J. K. (2005). Educating the net generation. Boulder, Colo.: EDUCAUSE.

Orr, D., M. Rimini and D. Van Damme (2015). Open educational resources: A catalyst for innovation, Educational Research and Innovation, OECD Publishing, Paris.

Orr, D., Weller, M. and Farrow, R. (2018). Models for online, open, flexible and technology enhanced higher education across the globe - a comparative analysis. International Council for Distance Education. 
Ossiannilsson, E. (2019). Considerations for quality assurance of e-learning provision. In European Distance and E-Learning Network (EDEN) Conference Proceedings (No. 1, p. 222-230). European Distance and E-Learning Network.

Park, J. H., and Choi, H. J. (2009). Factors influencing adult learners' decision to drop out or persist in online learning. Journal of Educational Technology $\mathcal{E}$ Society, 12(4), 207-217.

Quinn, J. (2013). Drop-out and completion in higher education in Europe among students from underrepresented groups. An independent report authored for the European Commission. NESET: European Commission.

Rawls, J. (2009). A theory of justice. Harvard university press.

Rowland, S. (2006). The Enquiring University: n/a. McGraw-Hill Education (UK).

Sarıtaş, E., ve Barutçu, S. (2020). Öğretimde dijital dönüşüm ve öğrencilerin çevrimiçi öğrenmeye hazır bulunuşluğu: Pandemi döneminde Pamukkale Üniversitesi öğrencileri üzerinde bir araştırma. Internet Uygulamaları ve Yönetimi Dergisi, 11(1), 5-22.

Schaffert, S. (2010). Strategic integration of open educational resources in higher education. In Changing Cultures in Higher Education edited by D. Schneckenberg and U. D. Ehlers, (p. 119-131). Springer: Berlin, Heidelberg.

Sclater, N. (2010). The organizational impact of open educational resources. In Changing cultures in higher education edited by D. Schneckenberg and U. D. Ehlers, (p. 485-497). Springer: Berlin, Heidelberg.

Shyman, E. (2013). Beyond equality in the American classroom: The case for inclusive education. Lexington Books.

Snauwaert, D. T. (2002). Cosmopolitan democracy and democratic education. Current Issues in Comparative Education, 4(2), 5-15.

Speece, M. (2012). Learning style, culture and delivery mode in online distance education, US-China Education Review, A 1, p. 1-12, 2012.

Telli Yamamato, G. ve Altun, D. (2020). Coronavirüs ve çevrimiçi (Online) eğitimin önlenemeyen yükselişi. Üniversite Araştırmaları Dergisi, 3(1), 25-34

UNESCO (2002). Forum on the impact of Open Courseware for higher education in developing countries final report. 15 May1s 2020 tarihinde http:/unesdoc.unesco.org/images/0012/001285/128515e.pdf adresinden erişilmiştir.

UNESCO (2019). Guidelines for inclusion. Ensuring access to education for all. 28 Şubat 2020 tarihinde http://unesdoc.unesco.org/images/0014/001402/ 140224e.pdf adresinden erişilmiştir. 
UNESCO (2020). National learning platforms and tools. 17 May1s 2020 tarihinde $<$ https://en.UNESCO.org/themes/educationemergencies/coronavirusschoolclosures/nationalresponses $>$ adresinden erişildi.

Veen, W., and van Staalduinen, J. P. (2010). The Homo Zappiens and its consequences for learning in universities. In Changing Cultures in Higher Education (p. 323-337). Springer, Berlin, Heidelberg.

World Economic Forum (2018). The Global Competitiveness Report. 15 May1s 2020 tarihinde http://www3.weforum.org/docs/GCR2018/05FullReport/TheGlobalCompetitivenessReport2018.pdf adresinden erişilmiştir.

Wolter, A. (2013). Massification and diversity: has the expansion of higher education led to a changing composition of the student body? European and German experiences. Higher education reforms: looking back-looking forward, 202-220.

Yasmin, D. (2013) Application of the classification tree model in predicting learner dropout behaviour in open and distance learning, Distance Education, 34(2), 218-231.

Kaynakça Bilgisi / Citation Information

Altunoğlu, A. (2020). Yükseköğretimde kapsayıcılığın uygulanabilirliği üzerine bir tartışma. OPUS-Uluslararası Toplum Araştırmaları Dergisi, 16(27), 672-699. DOI: 10.26466/opus.755015 